\title{
A experiência complexa e os olhares reducionistas
}

\author{
The complex experience and the reducing \\ approaches to it
}

Brani Rozemberg 1

Maria Cecília de Souza Minayo 2

\footnotetext{
1 Coordenadoria de Planejamento e

Epidemiologia do Centro de Pesquisas Hospital

Evandro Chagas, Fundação

Oswaldo Cruz. Av. Brasil

4.365 - Manguinhos -

21045-900 - Rio de Janeiro

- RJ, Brasil.

brani@ensp.ficoruz.br

2 Vice Presidência de

Ambiente, Comunicação

e Informação, Fundação

Oswaldo Cruz.
}

\begin{abstract}
This article focuses an experience of illness and cure witnessed by the first author in a rural community of Nova Friburgo, Rio de Janeiro. The reported experience allows a view of its existential, social, cultural, psychological, biological and symbolic meanings both for the patient, her community and their relationship. The initial presumption of a strictly biological diagnosis and intervention was modified by a sole medical consultation, which acquired a therapeutical function through broadening the interpretation of the experience beyond the limits of a "scientific objectivity". The disease process had its turning point towards resolution at the juridical level. The fact that the recognition of other levels for the disease determination took place at the powerful space of medical consultation may have contributed to the patient's change of attitude towards herself and the community, leading to cure once she started to play a new social role legally legitimated. The reported experience is discussed in terms of the reducing approaches of health/ illness.
\end{abstract}

Key words Complexity, Health and illness determinants, Social and cultural factors
Resumo Este artigo analisa uma experiência de adoecimento e cura acompanhada pela primeira autora em comunidade agrícola do interior de Nova Friburgo, Rio de Janeiro. A experiência relatada permite entrever seus significados existencial, social, cultural, psicológico, biológico e simbólico tanto para a paciente quanto para sua comunidade e na relação com esta última. A expectativa inicial de diagnóstico e intervenção puramente biológicos foi modificada através de um único atendimento que teve a função terapêutica de ampliar a compreensão da experiência para fora dos limites de uma "objetivação científica" e o processo de cura acabou tendo seu ponto de resolução no nível jurídico. O fato de o reconhecimento de outras ordens de determinação na doença desta paciente ter ocorrido no espaço do atendimento médico pode ter concorrido para sua mudança de atitude frente a si mesma e à comunidade, e conseqüente cura, com base no respaldo oferecido pela grande força simbólica da consulta médica na legitimação de um novo papel social que ela passou a exercer. $O$ episódio é discutido em relação aos reducionismos na abordagem da saúde/doença.

Palavras-chave Complexidade, Determinantes de saúde e doença, Fatores socioculturais 
Não sabia que era impossível, foi lá e fez (autor desconhecido)

Este texto é especialmente dedicado aos profissionais de áreas técnicas e de serviços de saúde que buscam a pós-graduação em saúde pública. Em sua busca de aprimoramento profissional e de reflexões que aprofundem seus conhecimentos, esses profissionais se deparam, com freqüência, com uma "re-leitura" acadêmica de temas com os quais já lidam, e sobre os quais muitas vezes já acumularam vasta experiência empírica. $\mathrm{O}$ trabalho acadêmico destina-se a lhes prover distanciamento crítico, novos conceitos, e a chance de rever seu posicionamento frente à prática, levando a análises fundamentadas e refinadas desta última e da vasta gama de ordens de determinação nela implicadas. Costumo dizer que, após terem caminhado no "território", tais alunos são bem-vindos ao mundo dos “mapas”. Ocorre que, muitas vezes, o sofisticado discurso dos que são peritos em "mapas" lhes impressiona a tal ponto que sua prática no mundo concreto dos territórios se desqualifica, alimentando a distância entre "quem faz" e "quem pensa". Este texto tem o objetivo de lembrar que todos nós, acadêmicos ou não, estamos irremediavelmente inseridos no mundo dos territórios. E que saber ler mapas pode ser útil, mas não é tudo.

\section{Sobre os reducionismos}

Um dos temas centrais dos cursos de pós-graduação é o da demanda por olhares não reducionistas ao complexo mundo da experiência. No campo da saúde o reducionismo mais visado é o do saber biomédico, que classicamente comporta uma visão de saúde reduzida a de "ausência de doença”, privilegiando os determinantes biológicos em detrimento dos sociais na interpretação dos fenômenos saúde e doença. Para Tesser et al. (1998) a atual crise da atenção à saúde está ligada ao exercício cotidiano desse saber biomédico, cuja racionalidade procura "fatos" numa relação de causalidade linear e mecânica. A base do saber biomédico é no dizer de Queiroz (1986) “o paradigma mecanicista da medicina ocidental moderna”. Segundo Luz (1998) a objetivação científica das doenças instaurou um novo objeto para a medicina ocidental: é a doença o que interessa ao médico, não mais os adoecimen- tos e curas dos sujeitos doentes. A tal ponto a biomedicina deslocou-se do mundo real da vida cotidiana, vivida pelos sujeitos doentes, que a maior parte dos relatos dos doentes hoje é desconsiderada pelo profissional de saúde como constituinte de seu objeto de saber e prática (Tesser et al. 1998).

As conseqüências desastrosas desse paradigma que exclui a própria experiência dos sujeitos no âmbito da cultura em saúde são descritas em Illich (1995) e consagrada no termo "medicalização" da vida e da sociedade. Além da geração infinita de novas necessidades a serem satisfeitas exclusivamente por uma mediação técnica complexa e custosa e da conseqüente tecnificação do atendimento a serviço do capital industrial, outra conseqüência do positivismo mecanicista na biomedicina estaria na focalização da saúde-doença sempre no nível individual de responsabilização e de intervenção. Isso tem a ver com o fato de que um olhar fragmentado e intervencionista deixa pouco espaço para a compreensão do contexto onde se desenrolam, no mundo vivido, os processos saúde-doença.

Aproxima-se desse reducionismo biomédico um outro, também bastante visado no meio acadêmico que discute o binômio saúde-doença: a psicologização. Para exemplificar o reducionismo que a leitura psicologizante pode operar na experiência temos os numerosos casos de "depressão" diagnosticados que, às vezes, relacionam-se também com a carência de determinados nutrientes na dieta. Um olhar menos cuidadoso com as demais ordens de determinação (em especial com a tão visada biomedicina) pode deixar de lado o tratamento da privação de ferro, por exemplo, em favor de longas sessões de terapia analítica. Uma depressão não é menos depressão por ter um fundo nutricional associado, mas se a leitura da experiência for apenas psicológica a anemia não diagnosticada pode trazer mais problemas e reforçar a própria depressão.

Além disso, raramente ou nunca os enfoques psicológicos são aplicados ou valorizados na prática clínica porque o profissional não dispõe de tempo, preparo, ou de convicção sobre o valor de sua utilização (Tesser $e t$ al. 1998). De toda forma essa área do saber é marginal na biomedicina, ficando sob a tutela dos profissionais especializados. As abordagens que propõem a superação da dicotomia entre corpo e mente são reconhecidamente necessárias pois esta é uma questão central na 
crise da atenção à saúde. No entanto, concordamos com Tesser et al. (1998) que a agregação do referencial da psicologia e suas correntes à biomedicina não é suficiente para "remediar" o reducionismo na prática médica. Leituras psicologizantes respondem também pelo aprisionamento das questões de saúde/doença no nível individual de entendimento e consequentemente de ações. Mesmo reunidos, o saber biológico e o psicológico não esgotam todas as questões constitutivas do "adoecimento" dos sujeitos. Outras ordens de fatores, outras instâncias de relações, envolvendo o ser humano, sua cultura, seu entorno social e ambiental, por exemplo, não são necessariamente contempladas.

Assim como o reducionismo biomédico, o psicológico tem também em sua base uma forte orientação positivista. Para fazer frente ao positivismo inúmeros movimentos teórico-filosóficos desenvolveram-se (Tesser, 1997), o que, segundo o autor, não foi suficiente para atingir o "império da biomedicina" e influenciar sua prática.

Menos visado que os demais, até porque é menos freqüente, o reducionismo operado pela sociologia também é digno de nota. Por décadas esquivou-se da questão do sujeito da saúde, ou seja, abdicou de pensar sobre o nível individual da assistência. Para Assis (1998) o discurso crítico na saúde não negou a questão do indivíduo, apenas tendeu a não enfrentar o tema talvez para fugir do risco de uma prática considerada reacionária e de uma identificação com o paradigma da biomedicina. Esta última tende a ser fortemente orientada para as "mudanças de comportamento individual" sem tratar das estruturas e das relações sociais que possam estar na base e contribuir para os padrões de comportamento que se quer modificar. A compreensão das questões coletivas determinantes dos quadros de saúde/doença era (e até hoje o é) tão incipiente e negligenciada, que a sociologia focalizou-as estritamente. O caminho da luta social e política era a única verdade e a meta era o resgate do "social" e a formação de "consciência crítica”. Fazer frente aos avanços da medicina (sua cultura e seus interesses) e ao seu grotesco esquadrinhar da experiência complexa de fato é tarefa que exige fôlego. Mas assim como as demais ciências, a sociologia na prática é outra. Faltaram sem dúvida mediações apropriadas que pudessem transformá-la em abordagem integradora. Ao advogar a "determinação so- cial" das doenças procede também uma redução da experiência negligenciando a questão do sujeito e de sua interação no sistema produtivo e na vida social. Além disso, o reducionismo sociológico no que tange ao componente técnico de suas ações não deixou de ser normativo. Segundo Assis (1998) continuava voltado para a obtenção de produtos, sendo que estes deixavam de ser "mudança de comportamento" e passavam a ser "conscientização". Mesmo quando visava facilitar a participação popular no planejamento e fiscalização dos serviços de saúde, deixava de problematizar o ponto de vista do sujeito e o significado para ele dos programas e conteúdos que lhe são propostos.

Pelo que foi exposto até aqui, compreende-se que o "reducionismo" não é um privilégio de área alguma do saber em particular. Ele é condição mesma do ato de conhecer, pois assim que racionalizamos algum aspecto da experiência, mesmo que momentaneamente, excluímos os demais. Ao focalizar a atenção na tentativa de apreender algum aspecto da experiência nosso olhar é necessariamente redutor dessa experiência. O maior problema, ao nosso ver, não está, portanto, no reducionismo em si, mas na pretensão de totalidade e de controle que as correntes de pensamento tendem a advogar para si mesmas e ainda, na instituição de uma forma de ver o mundo sob um determinado ângulo, desconhecendo e desqualificando outros olhares (ou até mesmo o nosso próprio em outro momento ou contexto). Tratamos aqui do termo reducionismo exatamente nesta perspectiva, a de pretensão de verdade unívoca como foi dito acima seja sobre o olhar estritamente biomédico, psicológico ou sociológico para o adoecimento.

$\mathrm{O}$ exposto nos remete necessariamente à importância da interdisciplinaridade e de como ela se operacionaliza no campo da assistência e da promoção da saúde. As diferentes leituras realizadas (mapas) deixam-nos pouco otimistas quanto ao que possa estar ocorrendo no campo do atendimento médico (território) nos serviços de saúde disponíveis à população. A razão deste artigo é partilhar nossa surpresa favorável ao testemunhar ao acaso um atendimento onde a visão não redutora e a atenção ao relato da história de vida da paciente prevaleceu e ampliou a questão da saúde para outros campos. 


\section{Análise de uma experiência}

Este trabalho tem como objetivo o relato despretensioso de uma experiência de adoecimento e cura que tivemos a oportunidade de acompanhar logo nos primeiros meses de convívio em um vilarejo agrícola do interior do município de Nova Friburgo. Nosso interesse em colaborar levando para o Rio de Janeiro a pessoa doente que chamaremos aqui de Délia (29 anos) acabou permitindo que assistíssemos sua consulta médica em hospital público e acompanhássemos o desfecho inusitado do caso.

\section{O quadro clínico e diagnóstico segundo a comunidade da qual Délia faz parte}

Depois de alguns meses de familiaridade com a comunidade agrícola tomamos conhecimento da doença de Délia. Aos poucos os vizinhos iam nos fornecendo um quadro bastante preocupante que incluía emagrecimento, desmaios, fraqueza, queda de pressão, feridas pelo corpo, "queimação" na urina, inapetência, crises de choro, crises de nervos etc. Todos comentavam que Délia estava com AIDS mas informavam também que "ela dizia" ter feito um teste para HIV que deu negativo, porém "não o mostrou a ninguém".

Os comentários sempre incluíam referências ao período que Délia passou "descasada" quando bebia e saía com vários homens diferentes e de fora da comunidade. Incluíam também críticas ao seu fracasso como esposa no primeiro casamento (com um rapaz da comunidade), pois ela "não cozinhava", não cuidava da casa e não sabia "cuidar da filha pequena" que já nos anos do casamento foi praticamente criada pela avó paterna.

Délia foi uma das primeiras mulheres da comunidade, se não a única na época, a se separar por desejo próprio, apesar dos esforços e da insistência do marido para manter o casamento. Casaram-se muito jovens e quando Délia o abandonou, voltando para a casa dos pais, deixou com ele a filha de dois anos, que acabou sendo criada mesmo pela avó paterna. Os comentários dos vizinhos estendiam-se sobre a família de Délia, uma das mais pobres da comunidade cujos membros estavam sempre doentes e "sofriam dos nervos".

Os vizinhos, penalizados com a doença de Délia, que se arrastava há quase um ano, se quotizaram para a compra dos remédios caríssimos dos quais ela necessitava. Eles davam a ela o di- nheiro e ela mesma comprava seus remédios. Os comentários na comunidade davam a entender que se tratava de medicação para AIDS.

Conhecendo melhor Délia e seu atual marido, um rapaz de fora da comunidade com quem estava casada há dois anos, confirmamos quase todos os comentários ouvidos da comunidade. Ela realmente abandonou o marido e a filha pequena; teve vários parceiros sexuais antes de casar-se de novo; sofria de todos os sintomas acima; tinha uma família paupérrima na qual todos sofriam dos nervos e de "ursa" (úlceras no estômago e duodeno); e também ela e o marido suspeitavam de AIDS, ainda que tivessem obtido um resultado negativo. Ambos eram extremamente gratos à comunidade pela compra dos remédios. A informação nova obtida no contato com Délia veio por escrito: o rótulo dos remédios caro esclarecia que ela tomava medicação apenas para herpes e infecção urinária e ainda, que seu teste realizado recentemente para HIV era realmente negativo.

Desconfiando de um falso negativo, o casal e a comunidade nos pediram para levar Délia a um médico e a um laboratório "bom" no Rio de Janeiro para refazer o exame e descobrir afinal "o que ela tem, antes que seja tarde demais". Sabendo que o Centro de Pesquisas Hospital Evandro Chagas onde trabalhamos, realiza atendimento à pacientes portadores do HIV, marcamos a consulta.

\section{A consulta médica no Centro de Pesquisas Hospital Evandro Chagas}

Por problemas na conciliação de agendas com os médicos e ainda com a disponibilização de um carro da prefeitura de Nova Friburgo para a viagem, mais de um mês se passou até a realização da consulta médica (Délia pediu que a primeira autora estivesse com ela durante o atendimento). Nessa fase intermediária nos impressionamos com seu estado geral. $\mathrm{O}$ rosto estava ainda mais pálido, as olheiras mais profundas, a pressão baixava bruscamente ocasionando desmaios, a queimação na urina se acentuou apesar de toda a medicação que ela já utilizava, e seu peso era $45 \mathrm{~kg}$ incompatível com sua altura resultando em aparência cadavérica. Os comentários da comunidade não lhe davam muito tempo de vida e havia muita expectativa em nossa viagem para o Rio de Janeiro.

Quando a viagem aconteceu chegamos ao hospital e esperamos na fila por duas horas ou 
mais. Nosso primeiro pedido à médica que nos atendeu foi um novo teste para HIV. A surpresa que tivemos com o atendimento recebido e suas decorrências motivou a redação deste relato. A médica "descobriu" que Délia estava magérrima por que não comia e disse a ela que "saco vazio não fica de pé". O motivo dos desmaios era exatamente esse. Não influenciada pela comunidade, a médica foi a primeira que "acreditou" no resultado negativo do teste de HIV. Evidentemente, se prontificou a fazer um novo pedido desse exame, bem como de toda a bateria de exames possíveis para nos contentar. Mas sua preocupação era saber por que a moça queria se matar por inanição. Ela não se contentava com as respostas obtidas: "porque não consigo comer" ou "porque se eu comer vomito". Ela não se deteve nos dados "clínicos" e o foco da consulta não foi a objetivação científica de uma doença. Sua consulta focalizava a doente e não a doença. Ela estava menos interessada do que nós nas doenças e não havia sinal de qualquer reducionismo biológico no seu olhar para a paciente.

Perguntou então há quanto tempo esses sintomas estavam ocorrendo e soubemos que tudo começara havia cerca de um ano. "O que mudou na sua vida há um ano atrás?”, perguntou a médica. Soubemos que foi por ocasião do casamento do pai de sua filha com uma mulher da comunidade que "assumiu" a educação da criança, restringindo em muito o contato entre Délia e a filha, agora com 9 anos. "Antes disso, eu podia vê-la quando quisesse na casa da avó". As visitas passaram a ser restritas a uma parte dos fins de semana, porém a madrasta sempre inventava algum outro compromisso para a filha de Délia justo no horário de deixá-la com a mãe. Eram tarefas domésticas, missa ou até mesmo limpeza da igreja. Além do pouco contato, Délia sabia que a criança era agora obrigada a fazer limpeza e lavar louça, obrigações que ela própria odiava e não cumpria. Na consulta toda a culpa pelo abandono da filha veio à tona e todos choravam com Délia. Dentre as coisas ditas pela médica, muitas frases ficaram marcadas: "De que vai valer para a menina ter a mãe morta?"; "Você não precisa de remédios e sim de sua filha"; "Cuide-se, alimente-se e fique forte para lutar pelos teus direitos como mãe". Na verdade, Délia e seu novo marido não queriam brigar pela guarda da criança (por serem muito pobres) mas sim pelos finais de semana e férias que não estavam sendo respeitados. $\mathrm{Na}$ consulta ficamos sabendo de um episódio que deflagrou uma das crises na saúde de Délia. Ela encontrou com a filha no ônibus da localidade e a madrasta não deixou que sentassem juntas. A criança por sua vez tinha medo de expressar seu amor pela mãe na frente do pai e de sua família pois ouvia dizer que a mãe "não prestava".

\section{O “tratamento" de Délia}

Todo o exame realizado deu negativo e o tratamento do herpes foi suspenso pois não havia mais sintoma ou manifestação que justificasse o uso das drogas. No entanto, a consulta resultou em um tratamento radical por iniciativa da própria paciente com base no ocorrido na consulta: a explicitação de sua “doença”. Só que o doutor que ela procurou não era médico e sim advogado! Na justiça, ela conseguiu reaver seu direito de ter contato com a filha. A relação entre as duas se estreitou, Délia conseguiu se perdoar por sua negligência como mãe no passado. Com a ajuda do marido se alimentava regularmente, recuperou peso, não fez mais o quadro de sintomas graves e não mais desmaiou. Teve uma recuperação rápida e ficou muito agradecida à médica e a nós que a levamos para a consulta. Sempre repete as frases da médica que ficaram como um marco em sua história de vida. Quanto à médica, apenas comentou ter sido esse um caso típico de psicossomática. Eu me pergunto se ela atende dessa forma todos os seus pacientes e se esse perfil de médico da rede pública é comum ou se estive diante de uma "raridade".

\section{A reação da comunidade}

Délia havia assumido o papel de indivíduo-sintoma, ou seja, aquele no qual todos projetam seus próprios fantasmas e que passa a cumprir a função expiatória em um grupo. Quando voltamos da consulta e dissemos que a moça não tinha doença grave, percebemos um misto de alívio e decepção nas pessoas, em especial na família do ex-marido. Têla com uma doença grave e ajudá-la com doações para compra de remédios era bem mais fácil do que partilhar com ela a educação de uma criança da comunidade! Délia havia feito tanta bobagem e ferido de tantas formas as regras de conduta daquele grupo social que o "castigo" da doença grave era uma solução mais fácil para sua exclusão do convívio. Nos 
últimos tempos dos sintomas "da doença grave", a comunidade encontrava inclusive o argumento do "contágio" para evitar que Délia se aproximasse da filha. Mas o que a família do marido procurava evitar era outro tipo de contágio: o dos valores culturais alheios aos da comunidade. Com a madrasta a vida da menina era "perfeita" para os moldes locais: lavar, cozinhar, deixar a casa brilhando, cuidar do irmão de criação e ajudar na lavoura do inhame. Com Délia a menina não aprenderia nada disso e ainda, conviveria com um homem "de fora" que ninguém sabe "de que família veio" e que não é agricultor.

Quando Délia obrigou o ex-marido e a exsogra a comparecerem em audiência por intimação judicial para assumirem frente ao juiz um acordo de respeito aos direitos de contato periódico entre mãe e filha, todos os seus "pecados" do passado foram expostos e uma grande confusão foi deflagrada na comunidade. O ex-marido, que antes chegou a colaborar na compra dos remédios agora a ameaçava de morte, e até mesmo nós, por um curto período, fomos vistas como quem "apoiou" a "desviante da ordem" naquela sociedade. Mas todos acabaram tendo que "engolir" Délia em seu novo papel de mãe de sua filha.

\section{Discussão}

A experiência analisada permite entrever seus significados existenciais, sociais, culturais, psicológicos, biológicos e simbólicos tanto para a paciente quanto para sua comunidade e na relação com esta última. O que ressalta mais fortemente da narrativa é a força coercitiva dessa comunidade onde Délia vive sobre seu foro individual, exercendo um domínio moral sobre normas de conduta e práticas sociais. Numa localidade pequena, onde as possibilidades de preservação da vida privada são limitadas e os comportamentos são estruturados por tradições e costumes rígidos, as categorias "certo" e "errado" estão dadas a priori, provocando um constrangimento profundo em cada um de seus membros.

No julgamento de qualquer atitude desviante, a pessoa, na sua totalidade, é aceita ou rejeitada. Aceita, se porventura se enquadra. Rejeitada por inteiro, mesmo quando é apenas um tipo de atitude sua que não se adequa aos usos e costumes. Dumont (1972) em Homo hierarchicus busca compreender e teoriza sobre a forte coerção exercida sobre os indivíduos em sociedades onde as funções, as hierarquias e as atribuições são rigidamente estabelecidas, deixando pouco espaço de liberdade para expressão (não prevista) das pessoas. Em contraposição, analisa também o que denomina "sociedades igualitárias" nas quais os indivíduos são o núcleo propulsor e o sujeito das organizações da comunidade. Duarte (1986) traz para o âmbito brasileiro, o pensamento de Dumont considerando que na cindida sociedade nacional, a lógica hierárquica tende a presidir as relações nas classes populares urbanas e rurais, onde são pouco permitidas expressões individuais diferenciadas, sobretudo quando põem em xeque a reprodução ideológica, o poder dos chefes ou dos mais velhos, ou dos usos e costumes rigidamente internalizados. A interdição sobre os dissidentes pode ter várias repercussões.

Uma forma freqüente de manifestação de mal-estar é o adoecimento. Alguns antropólogos têm estudado e analisado essa questão. Por exemplo, Lévi-Strauss, ao introduzir a obra de Marcel Mauss, faz o seguinte comentário: o esforço irrealizável, a dor intolerável, o prazer ou o aborrecimento são menos função das particularidades individuais que de critérios sancionados pela aprovação ou desaprovação coletivas. (1974). E acrescenta: em face das concepções racistas que querem ver no homem o produto de seu corpo, mostra-se, ao contrário, que é o homem, sempre e em toda a parte, que faz de seu corpo um produto de suas técnicas e de suas representações (1974).

Essa reflexão de Lévi-Strauss veio a propósito de um belo texto intitulado L'idée de la mort no qual Marcel Mauss analisa a maneira como tribos neozelandesas e australianas, regidas por uma lógica hierárquica, concebem os fenômenos da doença e da morte. Sobre elas existem várias explicações e uma delas está vinculada a causas sociais. Essa é construída pela idéia de uma ligação direta entre a esfera física, a psicológica e a moral. Ou seja, o medo da morte de origem puramente social pode criar tais manifestações mentais e físicas na consciência e nos corpos dos indivíduos, que eles podem realmente adoecer e morrer. São casos acontecidos de mortes causadas brutalmente em numerosos indivíduos, mas simplesmente pelo fato de que eles souberam ou acreditaram que iam morrer (Mauss, 1974). Mauss comenta que observou nessas sociedades um fenômeno singular, em que muitas pessoas fi- 
cavam possuídas de doenças causadas por feitiços, encantamentos ou pela consciência do pecado. $\mathrm{O}$ adoecimento acontecia pela introjeção da consciência de infração, de tal forma que o sujeito se enfermava ou morria, não por problemas biológicos, mas por causas atribuídas coletivamente. Em geral, o mal que o acometia vinha da consciência de ruptura com as crenças e representações consideradas boas, certas e justas pela comunidade de origem e convivência.

No mesmo sentido, Mary Douglas constata que o corpo social limita a forma pela qual o corpo físico é percebido. A experiência física do corpo, sempre modificada pelas categorias sociais através das quais é conhecida, sustenta uma visão particular de sociedade (1971). Por isso, a contribuição da antropologia permite dizer que há uma ordem de significações culturais mais abrangente que informa o olhar a ser lançado sobre o corpo que adoece e morre. A linguagem da doença é, em primeiro lugar, uma linguagem sobre a cultura e as relações sociais, mas o fenômeno em si representa a síntese de uma complexidade dinâmica que se manifesta no corpo.

Interessante no caso em pauta é a percepção da médica, cuja sensibilidade se igualou à dos antropólogos que, por dever de ofício, devem "desnaturalizar" e compreender as relações aparentemente "exóticas" nas sociedades. Essa sensibilidade, que aqui se expressou, é o indício de que é possível romper o pensamento biologicista monológico, dentro do próprio contexto médico, sem, simploriamente cair na tentação contrária de acreditar que tudo se explica pelo "social" ou pelo "emocional". O "olho clínico" (para usar uma metáfora médica) distingue as várias razões sem reduzi-las a uma parte apenas.

$A$ expectativa inicial de diagnóstico e intervenção puramente biológicos foi modificada através de um único atendimento que teve a função terapêutica de ampliar a compreensão da experiência para fora dos limites de uma "objetivação científica" e o processo de cura acabou tendo seu ponto de resolução no nível jurídico. O fato de o reconhecimento de outras ordens de determinação na doença de Délia ter ocorrido no espaço do atendimento médico pode ter concorrido para a mudança de atitude frente a si mesma e à comunidade com base no respaldo oferecido pela grande força simbólica da consulta médica na legitimação de seu novo papel social.
O episódio descrito permite exemplificar as múltiplas ordens de determinação que podem estar presentes nos fenômenos do adoecimento e da cura.

1) Social e econômico - a pressão que uma sociedade pode vir a exercer na direção da constituição de um "quadro clínico" para seus elementos desviantes não se dá a ver tão claramente em populações urbanas em face das possibilidades de anonimato e da multiplicidade das relações e contatos sociais travados no cotidiano. Na pequena comunidade agrícola todos se conhecem e qualquer estranho que circule nas estradas de terra da região dificilmente escapa de ser abordado pelos mais velhos para responder à clássica pergunta: "Você é filho de quem?". Diante da impossibilidade do anonimato e do testemunho contínuo por parte da comunidade das ações cotidianas de todos os seus membros, os interesses coletivos ganham visibilidade e força de coerção na direção do cumprimento de papéis sociais estabelecidos. Tais papéis são adaptativos à reprodução social do grupamento agrícola cuja sobrevivência é razão direta do emprego da força familiar na lavoura e tarefas domésticas "de apoio".

2) Ético, moral e simbólico - a força de pressão social na direção do enquadramento de Délia como "doente terminal" tem origem no seu desvio da norma de conduta como agricultora, esposa e mãe no primeiro casamento. $\mathrm{O}$ agricultor com quem se casou na adolescência mantinha o estrito padrão de rotina do plantio do inhame, e sua nova esposa assumiu a educação da filha de Délia para o desempenho do papel tradicional da mulher do campo. Essa possibilidade de "resgatar" a criança para os moldes de comportamento adaptativos da aldeia em seu modo de produção era de interesse do grupo. Havia portanto uma "morte simbólica" e uma "morte social" decretadas para Délia ao negar tudo isso, e uma tendência coletiva a encarar sua suposta "AIDS" como punição para os pecados contra a maternidade e a fidelidade devida ao marido - "ideal" do ponto de vista da coletividade.

3) Emocional, psicológico e físico - Délia expressou fisicamente através da inapetência essa morte/negação da vida. Apesar de feliz no segundo casamento, ela entendia que também seu primeiro marido a havia tratado muito bem e com excesso de zelo, tanto quanto o atual. A razão que a fez separar-se era "fútil" do ponto de vista de sua coletividade, princi- 
palmente para uma mulher: ela não estava apaixonada. Depois de separada sua relação com a filha era mantida (antes da proibição da madrasta da criança), porém numa base de igual para igual: duas crianças que brincavam juntas. Mas essa relação era fonte de prazer e equilíbrio para ambas. O início dos sintomas datava exatamente da proibição do convívio. Toda a culpa e arrependimento então vieram à tona expressos em crises físicas, emocionais e, em menor escala, psicológicas.

4) Comportamental, clínico e jurídico - a consulta médica foi o ponto de reversão do processo de autoflagelo que segundo a médica estava prestes a se tornar um quadro grave. Ainda que o nível físico de determinação não tenha sido negado, quando a médica revelou a Délia "seu problema", teve início uma mudança radical de comportamento. De vítima passiva de uma doença Délia passou a agente ativo de uma série de erros, trazendo seu problema para o nível psicológico. Reconheceu também seus direitos de ver a filha periodicamente. Não se pode dizer que ela desconhecesse seu problema antes da consulta, porém a instância nova de reconhecimento "oficial" (frente à médica e à pesquisadora) de seus direitos criou um novo contexto de "evidência pública” e legitimação desses direitos. Já os passos seguintes ela deu em absoluto sigilo e sem receber qualquer aconselhamento nessa direção: procurou um advogado. Só soubemos da mudança de atitude de Délia por ocasião da intimação judicial dos envolvidos. Lutar por seus direitos passou a ser o seu objetivo e este foi efetivamente o tratamento que promoveu a cura.

\section{Considerações finais}

Do ponto de vista da discussão proposta para este artigo sobre "mapas" e "territórios", o caso narrado permite uma conclusão interessante: os olhares reducionistas podem estar onde menos se espera. Na doença de Délia, a comunidade, a paciente e até mesmo a primeira autora deste texto restringiram-se ao aprisionamento da questão no nível biomédico. Já a recolocação da experiência em toda sua complexidade deu-se justamente a partir daquele ator representante da biomedicina: a médica que a atendeu.

Contrariando a expectativa que a academia tende a ter sobre o olhar reducionista do médico e principalmente contrariando os ditames de sua própria formação profissional que sem dúvida educa o médico para um tal olhar, a profissional de saúde que atendeu Délia "escutou" mais do que "auscultou". A questão colocada por Póvoa (2000) para o atendimento médico "entre a escuta e a ausculta" neste caso realizou-se sem polarizações reducionistas. É possível argumentar que esta tenha sido uma situação de exceção, o que não temos meios de constatar, ou ainda, que pelo fato de o hospital onde ocorreu a consulta ser dentro de instituição de pesquisa os médicos ali partilhem uma visão de saúde diferenciada em relação a outros serviços. É preciso esclarecer que nossa escolha não foi influenciada, sabíamos apenas que o hospital oferecia atendimento específico para o HIV. Mesmo se considerarmos estar diante de uma ocorrência rara e esporádica, o mundo dos "mapas" não pode negligenciar que, lá em baixo, no território, a massiva exposição a inúmeros pacientes por dia possa estar promovendo não linear e mecanicamente a tecnificação do atendimento, mas de algum modo, a partir do contato estreito com a experiência dos pacientes, olhares menos limitados e polarizados do que advogamos em teoria.

\section{Agradecimentos}

À médica Marisa Matos Salgueiro do Centro de Pesquisas Hospital Evandro Chagas por ter realizado o atendimento que gerou este texto e permitido sua divulgação. 


\section{Referências bibliográficas}

Assis M 1998. Educação em saúde e qualidade de vida: para além dos modelos, a busca da comunicação. Estudos em Saúde Coletiva 169, 30pp.

Douglas M 1971. Natural symbols. Pantheon Books, Nova York.

Duarte LF 1986. Do nervoso nas classes trabalhadoras urbanas. Editora Zahar, Rio de Janeiro.

Dumont L 1972. Homo hierarchicus. Palladin Editions, Londres.

Illich I 1995. Nêmesis da medicina: a expropriação da saúde. Nova Fronteira, São Paulo, 121pp.

Lévi-Strauss C 1974. Introdução à obra de Marcel Mauss, pp. I-XXV. In Mauss M, Antropologia e sociologia. Epu/Edusp, São Paulo.

Luz MT 1998. Natural, racional, social: razão médica e racionalidade científica moderna. Campus, Rio de Janeiro, 232pp.

Mauss M 1974. Sociologia e antropologia,. Vol. I. Epu/ Edusp, São Paulo.

Póvoa E 2000. Entre a escuta e a ausculta: crítica à racionalidade médica a partir da medicina baseada em evidências. Projeto de dissertação de mestrado, Escola Nacional de Saúde Pública, Fundação Oswaldo Cruz, Rio de Janeiro, 34pp.

Queiroz MS 1986. O paradigma mecanicista da medicina ocidental moderna: uma perspectiva antropológica. Revista de Saúde Pública 20(4):309-17.

Tesser CD, Luz MT e Campos GWS 1998. Influências da biomedicina na crise da atenção à saúde: a dicotomia entre a doença do médico e a doença do doente. Série Estudos em Saúde Coletiva, no 177. Seminário de Cultura, História e Política. Rio de Janeiro: Instituto de Medicina Social, Universidade Estadual do Rio de Janeiro. 